\title{
Correction to: Neutral section passing strategy preventing inrush current for electric railway solid-state transformers
}

\author{
Hanyoung $\mathrm{Bu}^{1} \cdot$ Yejun Lee ${ }^{1} \cdot$ Younghoon $\mathrm{Cho}^{1}$ (D $\cdot$ Myung-Yong Kim ${ }^{2} \cdot$ Eunsoo Lee $^{2} \cdot$ Jin-Hyuk Park ${ }^{2}$
}

Published online: 30 November 2021

(c) The Korean Institute of Power Electronics 2021

\section{Correction to: \\ Journal of Power Electronics (2021) 21:1135-1143 \\ https://doi.org/10.1007/s43236-021-00261-5}

Due to an unfortunate oversight the acknowledgement has been given erroneously. It should read:

This work was supported by a grant (20RTRPB146050-03) from the Railroad Technology Development Program funded by Ministry of Land, Infrastructure and
Transport (MOLIT) of Korean Government. This work was supported by "Human Resources Program in Energy Technology" of the Korea Institute of Energy Technology Evaluation and Planning (KETEP), granted financial resource from the Ministry of Trade, Industry \& Energy, Republic of Korea. (No. 20194030202370).

The original article has been corrected.

The original article can be found online at https://doi.org/10.1007/ s43236-021-00261-5.

Younghoon Cho

yhcho98@konkuk.ac.kr

1 Department of Electrical and Electronic Engineering,

Konkuk University, Seoul, Korea

2 Korea Railroad Research Institute, Uiwang, Korea 